\title{
Pierre Anctil, Ira Robinson (éd.), Les communautés juives de Montréal: Histoire et enjeux
} contemporains Québec, Éditions Septentrion, 2010, 275 p.

\section{Stéphanie Tremblay}

\section{(2) OpenEdition} Journals

\section{Édition électronique}

URL : http://journals.openedition.org/assr/22862

DOI : $10.4000 /$ assr.22862

ISSN : $1777-5825$

\section{Éditeur}

Éditions de l'EHESS

Édition imprimée

Date de publication : 31 décembre 2011

Pagination : 91

ISBN : 9782713223273

ISSN : 0335-5985

\section{Référence électronique}

Stéphanie Tremblay, «Pierre Anctil, Ira Robinson (éd.), Les communautés juives de Montréal: Histoire et enjeux contemporains », Archives de sciences sociales des religions [En ligne], 156 I octobredécembre 2011, document 156-5, mis en ligne le 14 février 2012, consulté le 21 septembre 2020. URL : http://journals.openedition.org/assr/22862 ; DOI : https://doi.org/10.4000/assr.22862 


\title{
Pierre Anctil, Ira Robinson (éd.), Les communautés juives de Montréal: Histoire et enjeux contemporains
}

Québec, Éditions Septentrion, 2010, 275 p.

\author{
Stéphanie Tremblay
}

\section{RÉFÉRENCE}

Pierre ANCTIL, Ira ROBINSON (éd.), Les communautés juives de Montréal: Histoire et enjeux contemporains, Québec, Éditions Septentrion, 2010, 275 p.

1 Un peu plus de cent ans après l'arrivée de la première vague massive d'immigrants juifs au Québec, aucun ouvrage ne traçait encore, à l'heure actuelle, un portrait global de l'histoire de cette communauté au sein de la société québécoise - en particulier à Montréal où elle se concentre - et des divers enjeux ayant émaillé son évolution interne et ses rapports à l'autre. Certes, plusieurs recherches ont déjà abordé des thèmes liés au judaïsme dans le contexte québécois, mais la plupart d'entre elles se bornaient à des périodes spécifiques ou ne mettaient l'accent que sur certaines dimensions particulières, sans offrir de vue d'ensemble du «fait juif» québécois. C'est donc à cette tâche aussi complexe qu'impérative que se sont attelés les auteurs de cet ouvrage, lequel se veut «une synthèse des connaissances actuelles et sur l'identité juive à Montréal». Portant à la fois un regard historique, religieux, sociologique et communautaire sur le judaïsme montréalais, ce livre, rédigé dans un langage clair et convivial, est donc susceptible d'intéresser à la fois les néophytes désireux de s'initier à l'univers du judaïsme que les étudiants et les chercheurs qui souhaitent se référer rapidement à une source de données diversifiées et bien documentées.

2 En effet, les onze chapitres de l'ouvrage, convoquant autant les travaux de spécialistes du judaïsme que des études québécoises, abordent succinctement le judaïsme montréalais à travers plusieurs perspectives à la fois différentes et complémentaires. 
De facture plus historique, le premier chapitre (I. Robinson) présente une brève synthèse de l'histoire générale du judaïsme, de ses origines à la période contemporaine. Si ce texte offre l'avantage de condenser en quelques pages plus de quatre mille ans d'histoire, il fait aussi d'importantes ellipses historiques, ce qui le transforme plutôt en instrument de vulgarisation destiné à ceux qui entrent en contact pour la première fois avec cette question. De même, le texte suivant, traitant du judaïsme à Montréal (du même auteur), retrace le contexte d'implantation et les spécificités religieuses des couches successives d'immigrants juifs qui ont sédimenté, au sein de la société montréalaise, depuis les premiers Sépharades jusqu'aux Ashkénazes orthodoxes d'Europe de l'Est, en passant par les réformés et les conservateurs, puis les ultraorthodoxes et les hassidiques arrivés après la Seconde Guerre mondiale. Quoique brossé à larges traits, ce portrait du judaïsme montréalais permet d'emblée d'éviter au lecteur de poser un regard trop réducteur ou stéréotypé sur la communauté juive en mettant l'accent sur ses nombreuses nuances doctrinales et idéologiques.

3 Les rapports entre francophones et juifs dans le contexte montréalais font l'objet du texte suivant (P. Anctil), qui croise les regards sociologique et historique pour décrire l'évolution des relations entre ces deux groupes, longtemps hermétiques l'un à l'autre. En analysant les pleins et les creux de l'antisémitisme québécois, l'auteur observe étonnamment que parmi les Canadiens-français qui manifestaient le plus d'hostilité à l'égard des juifs se trouvaient ceux qui entretenaient le moins de contacts avec eux, incluant les membres de la bourgeoisie traditionnelle et le clergé, réfractaire à cette communauté pour des raisons théologiques. À l'autre bout du spectre, les francophones issus des milieux ouvriers affichaient plutôt une certaine sympathie à l'égard de plusieurs groupes juifs, entre autres en raison de leurs affinités politiques et de la convergence de leurs revendications syndicales. L'auteur montre plus loin le rôle important de «passerelle» entre «les deux solitudes» joué par l'arrivée des Sépharades marocains à compter des années soixante.

Dans le texte suivant, J.-P. Croteau se penche sur la délicate question de l'éducation en replaçant dans son dense contexte historique la création du réseau des écoles privées de la communauté juive dans l'espace montréalais. Souvent perçue comme une forme «d'anachronisme» dans un système scolaire désormais défini sur une base laïque, l'émergence des écoles juives, comme le montre bien l'auteur, a plutôt résulté d'une sorte de stratégie permettant à la communauté juive de s'aménager un espace dans le système d'éducation québécois, longtemps monopolisé par les seuls groupes catholiques et protestants. L'analyse proposée par l'auteur met toutefois très peu l'attention sur la dynamique actuelle des écoles juives, les défis qui les attendent de même que les débats actuels qu'elles suscitent, des ajouts qui auraient pourtant pu s'avérer fort intéressants.

5 Un peu plus loin, R. Margolis étudie le rôle joué par le yiddish à Montréal au cours du $\mathrm{xx}^{\mathrm{e}}$ siècle en illustrant la tendance croissante à la polarisation de cette langue vernaculaire entre un véhicule de transmission de la culture patrimoniale, notamment dans les arts de la scène, et un outil de verrouillage des communautés ultra-orthodoxes à l'égard du monde moderne. Ce déplacement de la place occupée par le yiddish au sein de la communauté juive reflète la dualisation plus large au sein du judaïsme montréalais entre les segments ultra-orthodoxes et hassidiques d'un côté, où l'on observe la plus importante croissance démographique, et les mouvements conservateurs et réformés de l'autre. 
6 Les trois chapitres suivants se centrent sur les apports de la communauté juive à la vie culturelle, littéraire (C. Ringuet), économique et syndicale de Montréal (B. Dansereau) ainsi que sur la place du leadership des femmes juives dans l'espace public de la ville (s. Zylberberg). Ces diverses recensions reflètent encore une fois le pluralisme interne du judaïsme montréalais, qui compte un foisonnement d'artistes issus de différents horizons et des organisations politiques aux desseins idéologiques contrastés, allant de militants prosionistes à ceux qui nient son rôle-clé dans la vie diasporique de la communauté.

7 L'ouvrage se clôt sur trois chapitres qui proposent une analyse démographique et socioculturelle de la communauté juive montréalaise (C. Shahar, M. Weinfeld et A. Blander) puis une exploration plus poussée des deux segments de la communauté qui affichent la croissance la plus marquée parmi l'ensemble des juifs montréalais: les Hassidim (J. Bauer) et les Sépharades - marocains - (Y. Cohen). Ainsi, on apprend, grâce au premier texte, que la ville de Montréal se distingue par la haute «qualité» de sa vie juive. En effet, en plus d'afficher le plus bas taux de mariages mixtes en Amérique du Nord, la communauté juive de Montréal entretient un profond attachement à l'égard d'Israël. Cette singularité de la vie juive montréalaise reflèterait le poids démographique considérable des communautés orthodoxes (et hassidiques) et sépharades, plus fortement impliquées dans la pratique religieuse et le maintien de l'identité juive que les Ashkénazes, plus libéraux. Malheureusement, les données convoquées dans l'étude commencent déjà à être périmées puisqu'elles sont issues du recensement canadien de 2001. Dans «Les communautés hassidiques de Montréal», J. Bauer affine la description de ces groupes ultra-orthodoxes, souvent associés à de multiples préjugés, en montrant entre autres l'importante diversité interne de ces adeptes d'une communion joviale avec Dieu. Y. Cohen termine l'ouvrage en mettant en lumière les paramètres de la re-construction identitaire des Sépharades au sein de l'espace montréalais, une nouvelle «mémoire» qui se fonde notamment sur l'utilisation du français comme langue commune et «le renforcement du sentiment de cohésion communautaire».

8 D'un point de vue général, si le défi de dresser un panorama de l'histoire et des enjeux actuels relatifs aux communautés juives de Montréal est globalement très bien relevé dans Les communautés juives de Montréal, nous pouvons toutefois regretter l'absence ou le manque d'approfondissement de certains aspects clés du thème traité de même que la présence subtile de certains biais.

9 Notre première réserve concerne le regard général posé sur les communautés juives de Montréal, qui semble souvent doublé d'une volonté de convaincre le lecteur de leur «contribution» positive au paysage culturel, politique et religieux de la ville. Ce ton mélioratif teinte tout particulièrement les chapitres abordant les apports culturels et artistiques des juifs, leur contribution à la sphère économique et syndicale et la place du leadership féminin dans la communauté. Or, ce parti pris, visant le rapprochement entre les Juifs et les autres Québécois, aboutit par moments à une présentation quelque peu idéalisée de la communauté, susceptible de fragiliser les assises proprement scientifiques de l'ouvrage. En outre, on remarque que l'image dépeinte de la communauté juive au fil des textes tend à se figer dans des analyses qui accordent une nette prévalence à leur évolution historique au détriment de leur dynamique actuelle. Cette relative mise en veilleuse de l'actualité entourant la communauté juive de Montréal, qui offrirait pourtant bien de la matière à analyser, vient-elle tout 
simplement d'un manque d'intérêt des auteurs ou plutôt d'une stratégie d'évitement des questions plus taboues ou conflictuelles? Quoi qu'il en soit, il nous semble que cette facette contemporaine de la présence juive à Montréal aurait mérité plus d'attention au sein des textes. Une certaine place aurait également pu être consacrée à l'exploration des enjeux susceptibles de moduler l'avenir de la communauté, dont l'augmentation du poids relatif des Hassidims et des Sépharades, la diminution des Ashkénazes et le problème du leadership communautaire, qui devient de plus en plus complexe dans un contexte où s'accentuent les clivages internes de la communauté.

Dans le même ordre d'idées, même si les directeurs de la publication évoquent en introduction l'importance d'explorer les relations entre les communautés juives et les autres Québécois, on constate avec une certaine déception que seulement un chapitre $\mathrm{du}$ livre se penche sur cette question (P. Anctil), et ce en adoptant encore une fois une approche essentiellement historique qui ne fait qu'effleurer les tensions actuelles, pourtant bien réelles. À la fin du livre, une question demeure sans réponse: quel est le regard des Juifs sur les autres Québécois? La question n'est en effet abordée que dans le sens inverse, par le truchement de l'histoire de l'antisémitisme au Québec. Pourtant les rapports sociaux entre les juifs et les autres Québécois ne peuvent être intelligibles qu'à travers la saisie complémentaire du regard que les premiers portent sur les autres "Québécois francophones», notamment en réaction aux transformations du nationalisme québécois ou au fait français - en lien entre autres avec le poids des lois linguistiques.

11 Enfin, une mise en lien plus systématique du cas de figure montréalais avec d'autres foyers de la diaspora juive dans le monde aurait certainement enrichi les recherches présentées ici en ouvrant des espaces de comparaison plus larges et en favorisant l'essor de nouvelles pistes de recherches. Cela dit, Les communautés juives de Montréal. Histoire et enjeux contemporains fournit, malgré ces quelques bémols, un tableau éclairant, synthétique et accessible d'une communauté en pleine mutation, encore largement méconnue. 